\title{
GEOPHYSICAL ASPECTS OF THE GEOTECTONIC PROCESSES IN THE VARDAR ZONE AND THE EASTERN MACEDONIAN ZONE
}

\author{
Blagica Doneva, Marjan Delipetrev, Gjorgi Dimov, Todor Delipetrov \\ Faculty of Natural and Technical Sciences, "Goce Delčev" University, \\ P.O.Box 201, MK 2000 Štip, Republic of Macedonia \\ blagica.doneva@ugd.edu.mk
}

\begin{abstract}
A b s t r a c t: The paper deals with correlation dependencies of individual parameters of the Earth's crust in relation to the depth of Moho-discontinuity. These model investigations used data about the territory of the Republic of Macedonia. In the models, the territory was divided in three zones based on its neotectonic geologic setting [1]. The analysis carried out for the correlation coefficients for individual zones made possible the separation of zones relative to one another.
\end{abstract}

Key words: correlation; Moho-discontinuity; Bouguer's anomaly; geotectonic model; digitation; regression

\section{INTRODUCTION}

This paper gives recent data about the internal structure of the Earth's crust in parts of the Vardar zone and the Eastern Macedonian zone obtained for the territory of the Republic of Macedonia. The following maps were used to supply data for modeling in the exploration work:

- Structural map of Mohorovicic discontinuity based on data of deep-hole seismic sounding (DSS) for the Republic of Macedonia [5]. donia.

- Map of Bouguer's anomalies, part of Mace-

Models for the Vardar zone and the Eastern Macedonian zone were made based on the regional geotectonic setting.

Modeling the depth of Mohorovicic discontinuity $M$ depending on the relief height and the value of the Bouguer's anomaly $\Delta g$ were carried out by correlation and linear regression analysis methods. The linear dependences used were:

$$
\begin{gathered}
M=a+b R ; \\
M=a+b \Delta g .
\end{gathered}
$$

The analysis indicates that the Vardar zone possesses a complex structure in the surface part, particularly in the depth of the Earth's crust. This complexity is most probably related to the young volcanism (Kožuf-Vitačevo et al.) and the penetra- tion of abundant intrusions along the deep fault dislocations as well as the existence of neotectonic structural forms (depressions) discovered in this zone which do not have an impact on Mohorovicic boundary,

The small correlation coefficient for $M=f(\Delta g)$ relationship for the models of the Eastern Macedonian zone can be interpreted by the strongly pronounced young volcanism in the area (the Kratovo - Zletovo volcanic area et al.) and the magmatic intrusions present which did not strongly reflect within the Mohorovicic boundary. Correlation of the surface relief to the Mohorovicic relief has not been identified either. The model of the Eastern Macedonian zone is characterized by its abnormal correlation of the relief to the Mohorovicic boundary - the relief height to increase but the Mohorovicic boundary to decrease. Such value of the correlation coefficient indicates that present day forms in the relief do not reflect within the Mohorovicic boundary $M$.

The correlation coefficient for $M=f(\Delta g)$ is greater than the correlation coefficient for $M=f(R)$ which indicates the great influence of the density pattern in the undercrust structures on the Mohorovicic boundary $M$ compared to the relief changes. 
It can be inferred that Mohorovicic boundary $M$ has a complex correlation dependence pronounced through many parameters which have mu- tual interdependence $M=f\left(P_{1}, P_{2}, \ldots P_{n}\right)$. A map of Mohorovicic discontinuity was made based on this exploration.

\section{EXPLORATION MODEL}

The linear regression analysis model was used in establishing the correlation relationships in defining a model for the Earth's crust based on geologic and geophysical data. In our efforts to establish, define and analyze the relationships between two or more parameters we must also study and compare the variations of the two parameters and measure their relationships. This paper deals with their correlation in order to see their relationships as well as their importance in defining the thickness of the Earth's crust [4].

It is well known that defining the depth of Mohorovicic discontinuity from regional as well as global (planetary) aspect calls for solving functional dependencies of $M=f_{1}(R), M=f_{2}(\Delta g)$, as well as relationships between $M$ and $\Delta g$. Deep seismic microprobe exploration carried out in individual regions indicated stronger or weaker correlation between individual parameters. Moreover, it differs from region to region and does not allow defining any strict functional dependence of $M=f(P)$ $(P$ - parameter) for the whole world. The complexity of exploring the Earth's crust, or defining a linear model, is due to the complex correlation relationships between the large number of parameters which influence its structure.

An analysis of the correlation of $M=g(R)$ indicates normal deepness of Moho-discontinuity (from 25 to $30 \mathrm{~km}$ ) above the platforms, with increased deepness of boundary $M$ (to $50 \mathrm{~km}$ and over) under high mountains where it binds beneath them and forms root of mountain systems. Therefore, a rise of boundary $\mathrm{M}$ as well as smaller depth (from 7 to $10 \mathrm{~km}$ ) is to be expected under the oceans.

The correlation between $M$ and $R$ is not very strong and varies from region to region. Apart from relief height density of rock complexes which build the Earth's crust play an important role in the deepness of boundary $M$. The correlation dependence between the extent of subsiding of boundary $M$ and Bouguer's anomaly $(\Delta g)$ is physically logical. Analysis of Bouguer's anomaly indicates that, globally, Ag is positive above ocean areas. A comparison of correlation relationships between $M=f$ $(R)$ indicates that the former displays higher correlation with respect to the latter.
Taking in consideration available data and stratification of Earth's crust and material collected from the territory of the Republic of Macedonia several models were made in order to define the correlation dependencies with respect to the relief height $R$ and Bouguer's anomaly $\Delta g$.

The following maps were used as sources of input data for the models and their digitation:

- Structural map of Mohorovicic discontinuety based on DSS for Macedonia - The map gave the digitized input data for parameter $M$.

- Map of Bouguer's anomalies of Macedonia (Scale $1: 500$ 000) [7] - The map was used to obtain input data for the models for parameter $\Delta g$, whereas data for parameter $R$ were digitized based on its topography.

All maps, including the map of Bouguer's anomaly, had the same scale.

With respect to the degree of accuracy of the maps used, data for parameters $R$ and $\Delta g$ are the most accurate.

Linear regression modeling was made with STATGRAPH computer program for defining correlation relationships of parameters [6]. Bearing in mind the tectonic regional setting of the territory of Macedonia, linear regression models for Western Macedonia, the Vardar zone and Eastern Macedonia were made for each model for given correlation dependence $M=f(P)$.

Geological data for the territory of Macedonia and the results obtained from the correlation coefficients lead to the conclusion that the area of Western Macedonia is a fairly homogeneous block both in the surface part of the Earth's crust and in its deep structure. The pre-sign for the correlation coefficient for the relation $M=f(R)$ indicates that this block has its own root, or boundary $M$ bends under the block. It can be said that the Vardar zone consists of a more complex structure in the surface part, particularly in the deep part of the Earth's crust compared to the aforementioned block. Most probably the complexity is related to the pronounced young volcanism (Kožuf-Vitačevo et al.) as well as the incursion of intrusions along fault dislocations which are abundant in the area, together with neotectonic structure forms (depres- 
sions) present in the zone which have no influence on boundary $M$.

The Vardar zone as a whole has an impact on boundary $M$. Its height is the smallest compared to those in the Western Macedonian and the Eastern Macedonian zones, so the boundary $M$ of this zone has the smallest deepness.

The small correlation coefficient for the relation $M=f(\Delta g)$ can be interpreted by the strongly pronounced volcanism in the area (the Kratovo Zletovo area) as well as neotectonic magmatic intrusions which did not largely influence boundary $M$. Similarly, there is no correlation between surface relief and boundary $M$ either. Conversely, abnormal correlation of the relief with boundary $M$ is characteristic for Eastern Macedonia. This means that the relief height increases whereas boundary $M$ reduces which is not the case with the other two zones. Such correlation coefficient indicates that present relief shapes do not influence boundary $M$.

The correlation coefficient for $M=f(\Delta g)$ is strongly related compared to correlation coefficient for $M=f(R)$, which indicates stronger influence of density pattern in undercrust structures on boundary $M$ with respect to the changes in relief or the crust structures on boundary $M$.

It can also be inferred that $M$-boundary has more complex correlation dependence pronounced by several mutually dependent parameters $(M=f$ $\left(P_{1}, P_{2}, P_{3} \ldots\right)$ (Figures 1-10, Tables 1-8).

Linear correlation dependence between deepness of Mohorovicic discontinuity $(M-$ given in $\mathrm{km})$ and relief height $(R$ - given in $\mathrm{km})$ were investigated in this model.

Digitized values of the parameters are given in appropriate squares, the first value is the relief height, the second is deepness of Mohorovicic discontinuity

Linear correlation dependence between deepness of Mohorovicic discontinuity $(M-$ given in $\mathrm{km})$ and Bouguer's anomaly $(\Delta g-$ given in $\mathrm{m} / \mathrm{s})$ were investigated in this model. Digitized values of the parameters are given in appropriate squares, the first value is the Bouguer's anomaly, the second is deepness of Mohorovicic discontinuity.

Table 1

Regression analysis - linear model (Western Macedonia): $y=a+b x$

\begin{tabular}{lccc}
\hline \multicolumn{2}{c}{ Dependent variable $-y$} & Independent variable $-x$ \\
\hline Parameter & Estimate & \multicolumn{2}{c}{ Standard error } \\
\hline Intercept $-a$ & -34.23 & 1.26 \\
Slope $-b$ & -2.97 & 0.81 \\
\hline \multicolumn{4}{c}{ Analysis of variance } \\
\hline Sodel & Sum of squares & Df & Mean variance \\
Error & 154.13 & 1 & 154.13 \\
Total & 711.09 & 62 & 11.46 \\
\hline Correlation coefficient $=-0.42$ & 63 & \\
Standard error of est. $=3.38$ & & \\
\hline \hline
\end{tabular}

Table 2

Regression analysis - linear model (Eastern Macedonia): $y=a+b x$

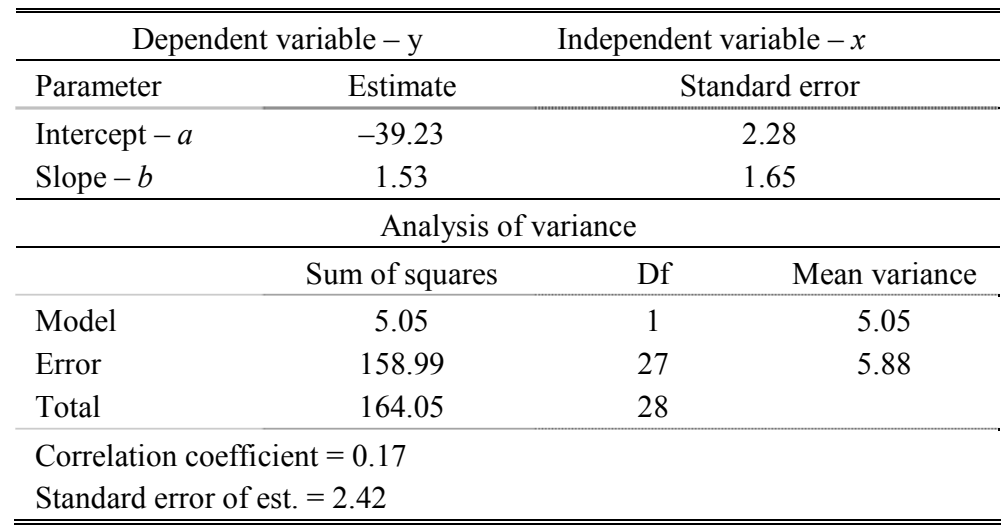






Fig. 1. Linear correlation model $a+b R$

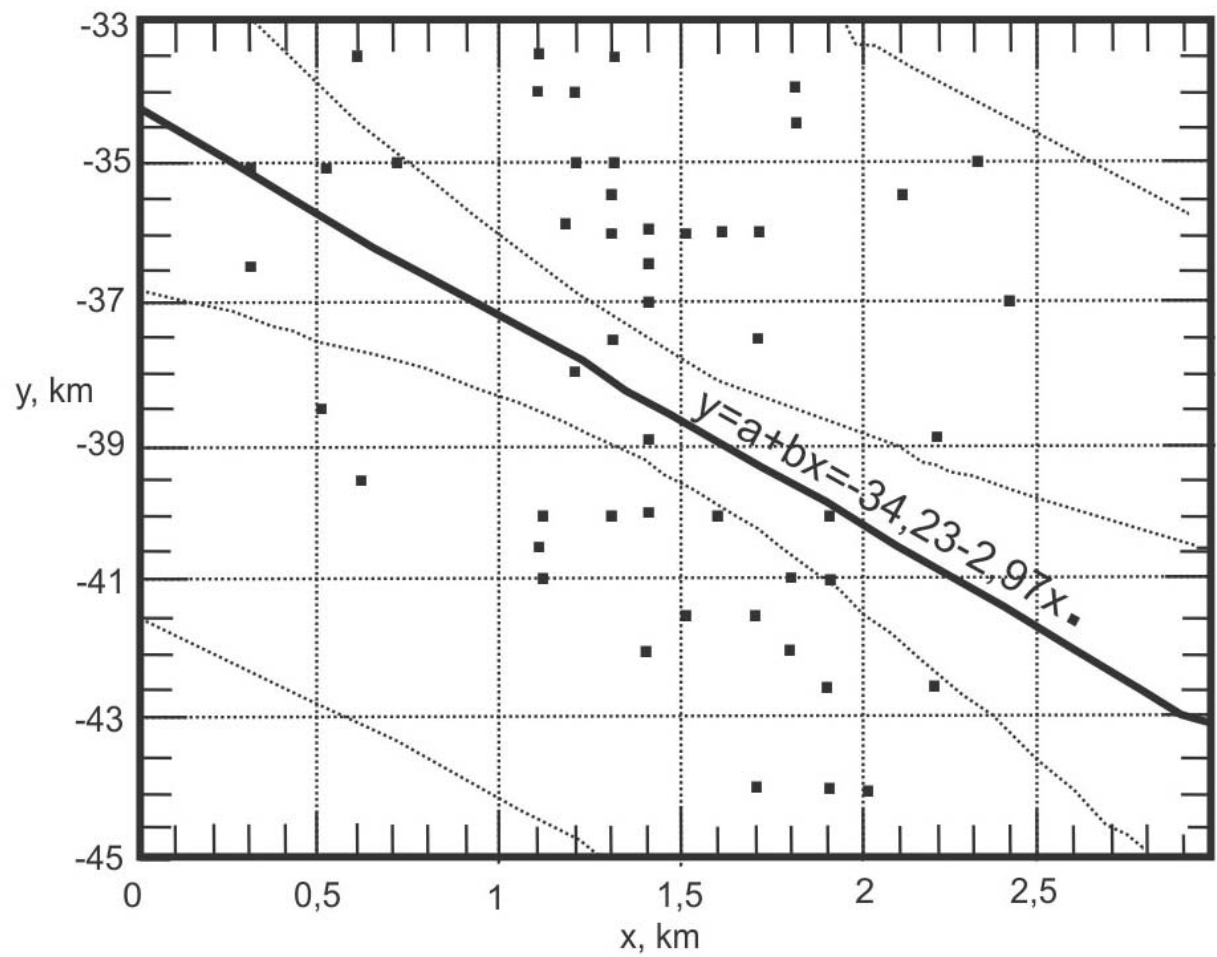

Fig. 2. Analysis of $M=y$ and $R=x$ for Western Macedonia 


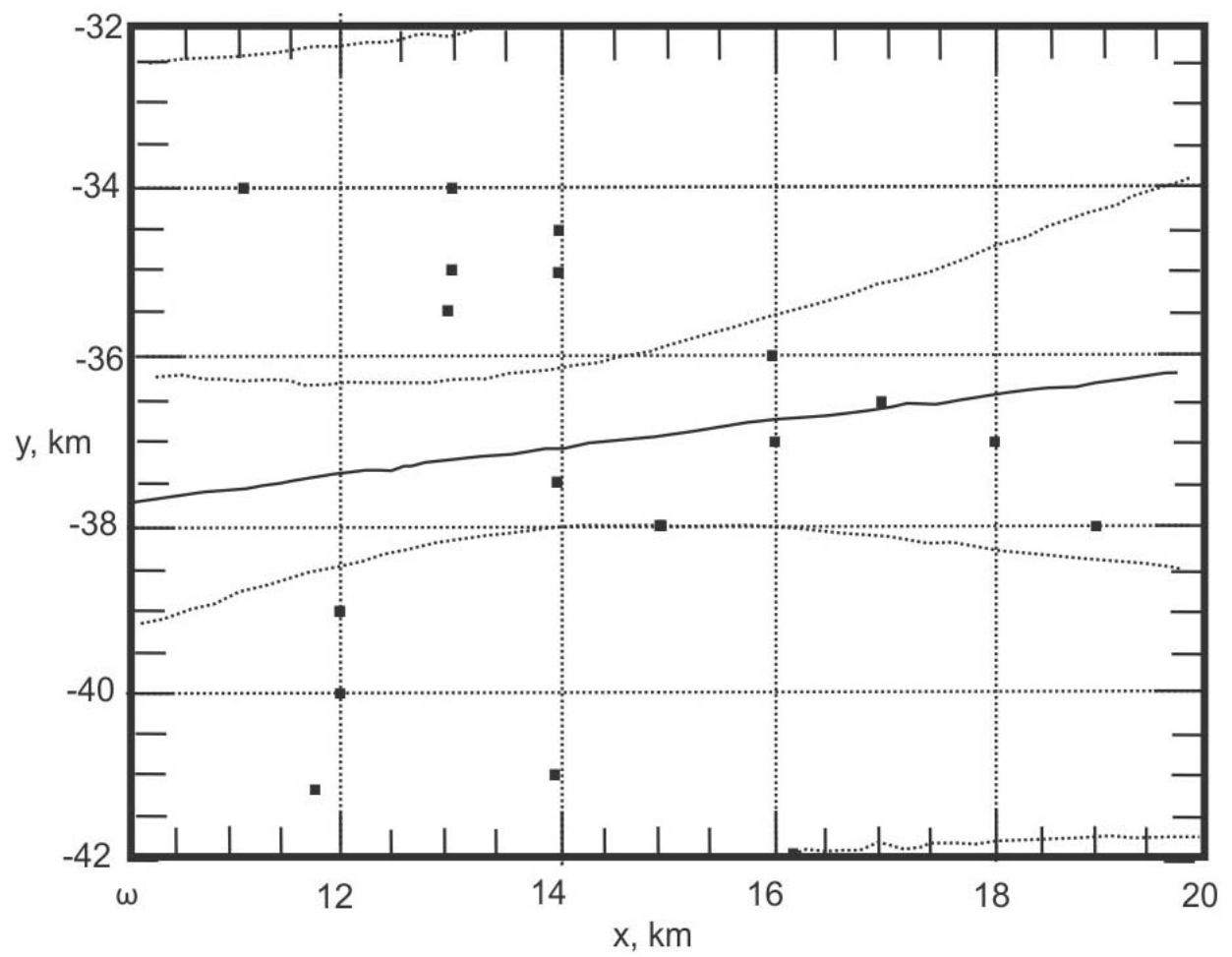

Fig. 3. Analysis of $M=y$ and $R=x$ for Eastern Macedonia

Table 3

Regression analysis - linear model (Vardar Zone): $y=a+b x$

\begin{tabular}{lccc}
\hline \hline \multicolumn{2}{c}{ Dependent variable $-y$} & \multicolumn{2}{c}{ Independent variable $-x$} \\
\hline Parameter & Estimate & \multicolumn{2}{c}{ Standard error } \\
\hline Intercept $-a$ & -31.54 & \multicolumn{2}{c}{0.40} \\
Slope $-b$ & -2.42 & 0.43 \\
\hline \multicolumn{4}{c}{ Analysis of variance } \\
\hline Sum of squares & Df & Mean variance \\
Error & 52.91 & 1 & 52.91 \\
Total & 102.68 & 60 & 1.71 \\
\hline Correlation coefficient $=-0.58$ & 61 & \\
Standard error of est. $=1.30$ & & \\
\hline \hline
\end{tabular}

Table 4

Regression analysis - linear model (Macedonia): $y=a+b x$

\begin{tabular}{lccc}
\hline \hline \multicolumn{2}{c}{ Dependent variable $-y$} & \multicolumn{2}{c}{ Independent variable $-x$} \\
\hline Parameter & Estimate & \multicolumn{2}{c}{ Standard error } \\
\hline Intercept $-a$ & -31.34 & \multicolumn{2}{c}{0.58} \\
Slope $-b$ & -4.16 & 0.44 \\
\hline \multicolumn{4}{c}{ Analysis of variance } \\
\hline Sum of squares & Df & Mean variance \\
\hline Model & 727.59 & 1 & 727.59 \\
Error & 1278.20 & 153 & 8.35 \\
Total & 2005.79 & 154 & \\
Correlation coefficient $=-0.60$ & & \\
Standard error of est. $=2.89$ & \\
\hline \hline
\end{tabular}




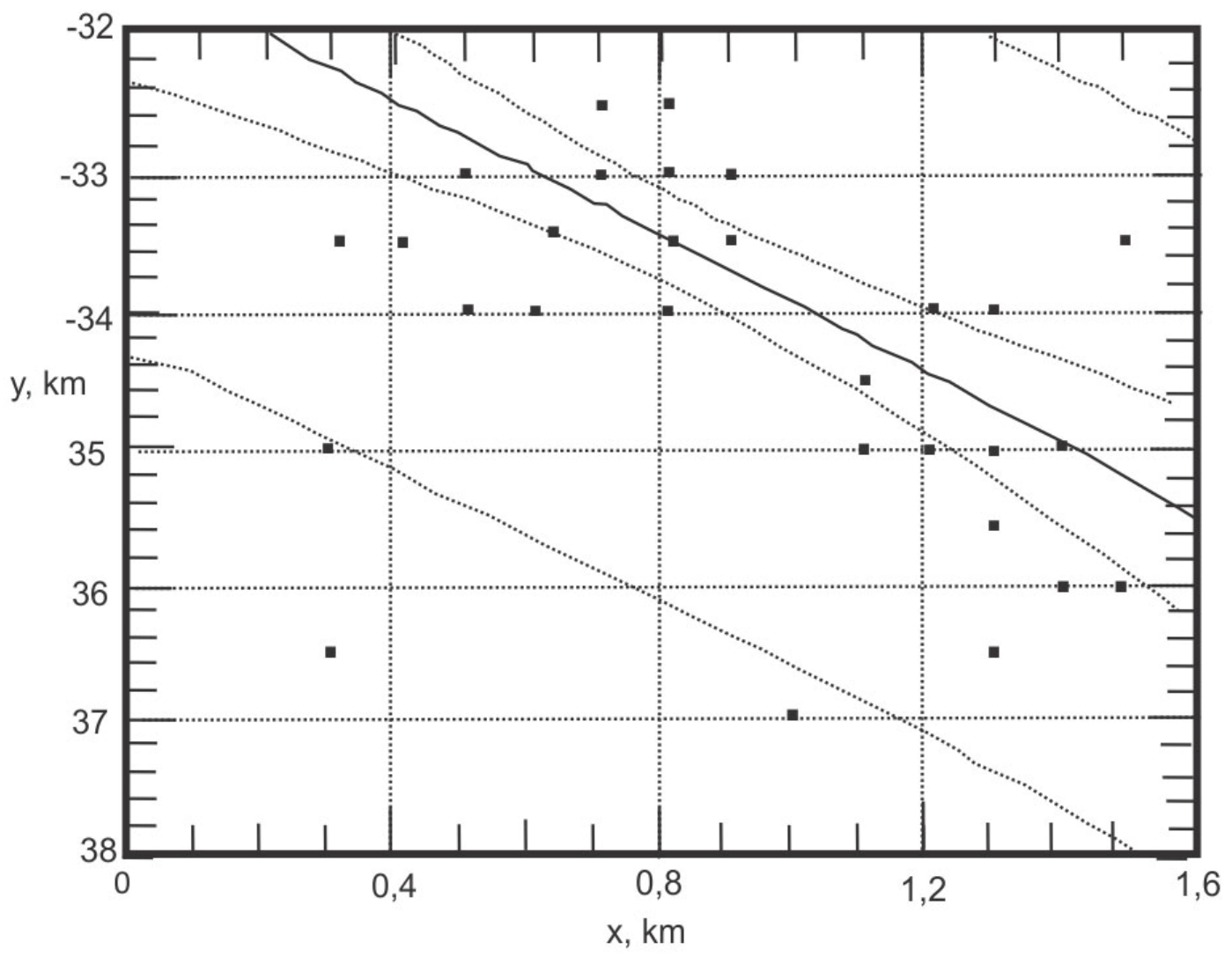

Fig. 4. Analysis of $M=y$ and $R=x$ for the Vardar Zone

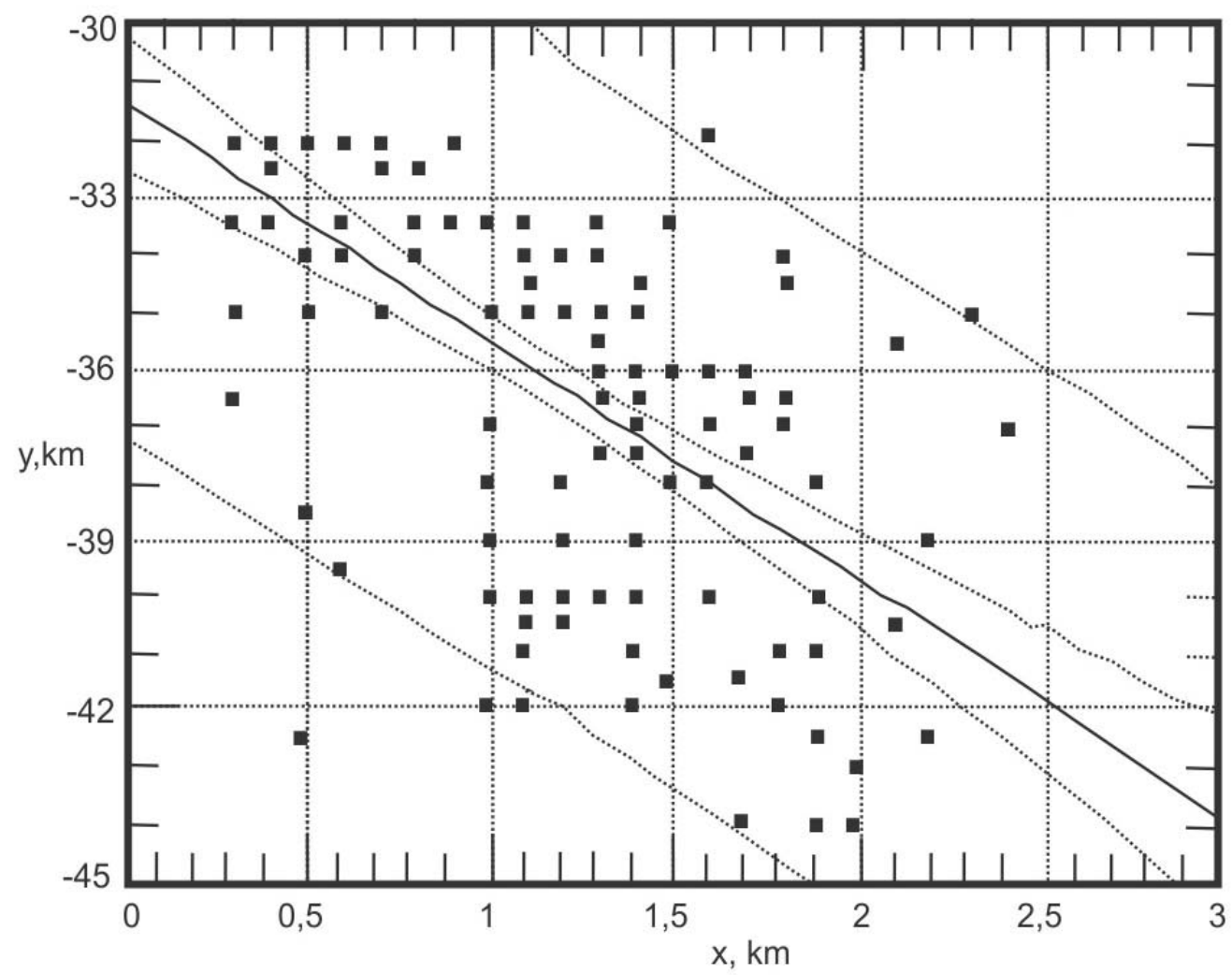

Fig, 5. Analysis of $M=y$ and $R=x$ for Macedonia 